\title{
Intense, Pervasive and Shared Faculty Dialogue: Generating Understanding and Identifying "Hotspots" in Five Days
}

\author{
Emily Janke, Barbara Holland and Kristin Medlin, MPA
}

\begin{abstract}
Once an institution has chosen to recognize and reward community-engaged scholarship in its universitywide promotion and tenure policy, what are some strategies for aligning unit and department policies as well? This chapter describes the path followed at The University of North Carolina at Greensboro to align policies across all units and departments. Discussed are core strategies used to generate faculty support for community-engaged scholarship in promotion and tenure policy and practice, the themes revealed as a result of a weeklong dialogue initiative, and recommendations for continued improvement.
\end{abstract}

\section{Introduction}

Embedding community engagement in promotion and tenure policies is a key indicator of institutional support for community-engaged scholarship (e.g., Holland, 2001; Furco \& Holland, 2004; Hollander, Saltmarsh, \& Zlotkowski, 2001). Such policies codify and perpetuate institutional culture. The interpretation of scholarship, particularly within the context of the promotion and tenure process, "defines the fundamental character of higher education institutions" (Holland, 1997, p. 38). The presence (or absence) of promotion and tenure policies that recognize and reward community-engaged teaching, research, and service activities is a major factor by which faculty determine whether their work is compatible and consistent with institutional expectations for involvement and achievements in community-university partnerships (Holland, 1995, 1997). O'Meara's (2002) study of communityengaged faculty found that faculty exemplars report increased satisfaction with work and their university. Faculty whose universities had adopted policies that supported community-engaged scholarship found that they: (1) experienced greater congruence between stated rhetoric institutional service mission and reward systems; (2) viewed their service as a potential form of scholarship; (3) felt elevated importance of service as scholarship in reward systems; (4) perceived greater proportionality of faculty workload; and (5) believed their community-engaged work was legitimized.

Community engagement and organizational change scholars have argued that if institutional policies are to affect individual and collective practice, then they must become aligned with and embedded into the culture of academic departments (e.g., Battistoni, Gelmon, Saltmarsh, Wergin \& Zlotkowski, 2003; Kecskes, Gelmon \& Spring, 2006; Furco \& Holland, 2004; Holland, 1997; Kecskes, 2006). It is possible to have policy change without cultural change. Departmental culture change is essential, particularly as colleagues evaluate the dossiers of their peers for promotion and tenure. It is where the "rubber meets the road."

The review and revision of promotion and tenure policies in ways that facilitate fair and equitable treatment of community-engaged scholarship, among other forms of emerging scholarship, is particularly relevant and significant given demographic trends in higher education. Higher education is in the midst of rapid faculty turn over as the baby boomer generation exits the academy over the next decade (Sugar, Pruitt, Anstee \& Harris, 2005). If institutions are to attract and retain diverse faculty populations, they must reflect the expectations for legitimate and valued academic work of the diverse incoming faculty. Many studies report the overrepresentation of faculty of color and women in the group of faculty involved in community engagement (e.g., Aguirre, 2000; Antonio et al., 2000; Baez 2000; Vogelgesang, Jensen \& Jayakumar, 2010). 
Despite the increased calls for recognizing community-engaged scholarship and the faculty, student, and community benefits such an approach to scholarly work may bring, significant challenges remain, even on campuses that have expressed initial support for newer forms of scholarship. This article describes the efforts of faculty and administrative leaders at The University of North Carolina at Greensboro (UNCG) to create a faculty culture in which community-engaged scholarship is seen as legitimate faculty work, and the quality of which can be assessed according to revised and aligned faculty promotion and tenure policies and practices. This required, among other accomplishments, the ability to establish common language and views of what constitutes high quality, community-engaged scholarship.

In this article, we illustrate UNCG's institutional context and processes through which communityengaged scholarship was embedded across faculty roles (teaching, research/creative activity, and service) in the university's promotion and tenure guidelines. This context is important for understanding the existing groundwork that was laid, and which likely maximized the success of the ensuing dialogues. Next, we describe the development and implementation of a weeklong intensive dialogue process that knitted together existing language and conversations internal to UNCG with information and legitimacy conferred through the external perspectives of a nationally-esteemed guest facilitator. We present several suggestions, based on UNCG's experience, to guide the work of other institutions to maintain systematic and informed efforts to move support for community-engaged scholarship from institutional rhetoric to collective practice and core academic culture.

\section{UNCG Case Example}

An urban metropolitan campus located centrally in the state and embedded within the most racially and ethnically heterogeneous city of North Carolina, The University of North Carolina at Greensboro (UNCG) is diverse in many ways. Over a quarter of its more than 19,000 students are non-White making it a minority serving institution, and over a quarter of undergraduates are older than 25 years of age. Students come from 48 states and over 80 countries enrolling in programs offered by more than 50 academic departments within 7 academic units. Grounded in a liberal arts educational approach, UNCG is home to professional schools including health and human sciences, nursing, education, and business, as well as a large and well-respected college of arts and sciences and a school of music, theatre, and dance, and a recently established school of nanoscience and nanotechnology (jointly shared with North Carolina Agricultural and Technical State University).

UNCG has long held the tradition of public service, first as the State Normal and Industrial School, second as Women's College, and now as UNCG. This history influences the conversations today about the transitioning identity of the university. In the past two decades, in particular, the balance of teaching and research has shifted to the point that UNCG is now categorized by the Carnegie foundation as a fouryear, doctoral granting, research university with high research activity. Faculty who have served at UNCG for decades comment on how the identity of the university has shifted from one in which it was teaching centered, to now having considerably more emphasis on traditional prestige indicators such as grants received and scholarship published as books or in peer-reviewed journals. Beyond the changes in the proportion of teaching compared to research in the tenure, review, and rewards systems and overall culture, they speak to the increased requirements for accountability, reporting, and other forms of university and professional service.

UNCG has also gained local, regional, and national recognition for its commitment as a communityengaged university, particularly in the past decade. The Carnegie Foundation recognized UNCG as a community-engaged institution in 2008 and 2015, and many faculty, staff, and administrators have received individual leadership positions and awards. The support of faculty and administrative 
"champions," many who called for the establishment of a service-learning center on campus over a decade ago, have more recently led significant efforts to integrate community-engaged faculty work into the core of faculty culture through the university's 2009-2014 strategic plan, as well as its promotion and tenure policies and practices.

\section{Catalysts for Promotion and Tenure Policy Revisions}

A combination of forces served to catalyze faculty members' efforts to revise the university, and ultimately unit and department promotion and tenure guidelines at UNCG starting in 2008. At this time many strategic initiatives were underway on the campus and beyond. The General Education Curriculum was under revision, including discussions to include civic learning goals. The 2009-2014 UNCG Strategic Plan was being written, in which Engaged Scholarship became a major goal with actionable plans. UNCG applied for the first time to the Carnegie Foundation for the elective Community Engagement classification, hence undertaking a large institutional study of engagement. Lastly, the UNC system's strategic visioning and planning process "UNC-Tomorrow" was underway, which asked universities to be responsive to the needs of the state in very direct ways.

Faculty Champions. It is important to note that in tandem with this institutional momentum, several longtime faculty champions of community-engaged scholarship held consecutive and aligned leadership positions in the Faculty Senate and the General Faculty, putting community-engaged scholarship and promotion and tenure on the agenda. Rebecca Adams, the chair of the Faculty Senate and the Strategic Planning Committee, appointed an ad hoc Committee on Nontraditional Scholarship to address the question of engagement. As an engaged scholar herself, Adams knew the challenges engaged faculty faced with regards to not getting adequate "credit" for their scholarship. As the chair of the strategic planning committee, Adams was also intimately aware of the UNC Tomorrow Response Planning document that asked universities to: (1) encourage faculty to address important societal issues, and reward them for doing that work well; (2) create incentives for faculty to engage in applied research, scholarship, and public service; (3) continue to support and reward basic research, theoretical scholarship, and creative activities; (4) make appropriate University faculty more accessible to small business owners, nonprofit organizations, K-12 schools, and community groups; and (5) continue to support the use of the tenure process as a way to validate that faculty candidates are highly qualified experts in their fields (UNC Tomorrow, 2008).

The ad hoc committee worked systematically and thoughtfully to propose revisions to the promotion and tenure guidelines, considering the many perspectives that constitute the UNCG scholarly community. They were also mindful that they wanted neither to convey that one form of scholarly activity was inherently more valuable than others nor that any individual faculty member would be required to engage in specific kinds of scholarship. Ultimately their aim was to revise the guidelines to be inclusive.

The Chair of the Nontraditional Scholarship Committee presented the process it would undertake to revise the guidelines to the Faculty Senate in November 2009. The committee was committed to addressing the issue of community-engaged scholarship in university policy, seeking input from informed engaged scholars, and reviewing the current guidelines to propose recommendations. The Chair also provided some guiding definitions, as at that time there was no single or commonly shared definition of community engagement or community-engaged scholarship. However, having just recently received designation as a community-engaged institution by Carnegie, the Committee quickly moved to use Carnegie's terminology (i.e., "community engagement") as its guide, and ultimately, definition (Carnegie, 2015). Over the period of the academic year, the Committee consulted with many groups across campus, including chairs of the promotion and tenure committees, faculty senate, deans' council, and executive staff, and held a well-attended faculty forum to describe the proposed changes. 
The following year, the incoming Faculty Senate Chair, Laurie Kennedy-Malone, chose "Promoting and Sustaining Scholarly Engagement" as her leadership theme. She wanted to see the hard work of the nontraditional scholarship and promotion and tenure committees continued. As chair of the senate, she cofunded a qualitative study that was conducted by the lead author and a service-learning faculty fellow to examine the experiences of 14 community-engaged scholars at UNCG (Janke \& Hayes, 2010). The purpose was to understand their experiences at UNCG, and specifically, (a) how they defined communityengaged scholarship; (b) their developmental journeys and scholarly products; and (c) their experiences with annual reviews, reappointment, promotion and tenure as engaged scholars. This study revealed that most of the faculty participants (1) brought their engaged practices to the academy through previous positions and professions; (2) experienced synergies by integrating their work with communities throughout their teaching, research, and service roles; and (3) received largely negative messages from senior faculty about the value of this work in promotion and tenure committees. Some participants shared that they were discouraged from doing this work prior to tenure, and nearly all of them spoke of the need to do "double duty" - the need to have sufficient numbers and eminence within traditional forms of scholarship, such as peer reviewed articles and books, to achieve promotion and tenure, because other forms of nontraditional scholarly products (e.g., reports, programs, websites, etc.) would likely not "count."

Speaker Series. As chair of the faculty senate, Kennedy-Malone also co-sponsored Amy Driscoll's visit to UNCG in 2010 to speak with various faculty and administrative leadership about how to support community engagement in conversations in promotion and tenure policies and practices. Like others national scholars before and following her (for example, Patti Clayton, George Mehaffy, John Saltmarsh, Tim Eatman, Barbara Holland, Judith Romaley, and Nadinne Cruz), Driscoll urged UNCG to take a scholarly praxis approach, iteratively engaging in dialogue and informed study of the process. She, like others, also encouraged the use of one integrated set of standards that cut across multiple forms of scholarship (e.g., Glassick, Huber \& Maeroff, 1997); a top-down and bottom-up approach; and the importance of open dialogue to surface underlying assumptions, fears, tensions, and commitments. Throughout all of these conversations leaders were careful to emphasize that the proposed revisions did not in any way mandate that faculty "do engaged scholarship" (e.g., the Provost in his introductions of speakers, faculty senate members in their opening statements in faculty forums and faculty senate meetings, and speakers themselves in their talks). Rather, leaders reasoned, it simply ensures that it is recognized as a viable form of scholarship, alongside others.

Institutional Definitions. In 2011, Janke (lead author) serving as the special assistant for community engagement to the vice chancellor for research and economic development, and Patti Clayton, a visiting scholar working with Janke at UNCG, were asked at a Dean's Council meeting by the Deans and Provost to draft a scholarly terms and definitions document. Janke and Clayton subsequently wrote a letter that was informed by faculty input (Janke \& Clayton, 2011). The definitions were widely distributed, shared at Faculty Senate, and posted on the Provost's webpage that hosts promotion and tenure policies and forms. Ultimately, a condensed version was included in the first volume in the Excellence in Community Engagement and Community Engagement series produced by (what is now) the Institute for Community and Economic Engagement (ICEE) (Janke \& Clayton, 2012).

The volume provides suggested language that integrates past and current UNCG discussions and policy with scholarly literature and national conversations. The goal of the volume is to address how community engagement may be achieved through the scholarly activities of research, creative activity, teaching, and service - and, how it may be defined within unit- and department-level promotion and tenure evaluation guidelines, non-tenure track faculty guidelines, faculty annual reports, unit mission statements, and other documents and policies. In particular, the volume addresses the question of "what is community engagement?", and "how are high quality community-engaged research, creative activity, teaching, and service distinct from community service or outreach?" 
Alignment among University, Unit, and Department Policies. Despite this progress, conversations about the alignment of unit and departmental policies and practices to the university-wide policy had not progressed. Nearly every national guest speaker UNCG hosted as part of the Community Engagement Series emphasized that this vertical alignment was "where the rubber meets the road." We believe this inertia was because faculty members make individual judgments and collective decisions about their colleagues in the context of their departmental, and to some extent, unit-level culture. If the department has not internalized and operationalized how to support documentation or evaluation of community engagement in a fair and equitable way, then it will not matter that a university-wide policy was created.

Aligning department to university policies was particularly critical for UNCG in which policy structures and culture were (at the time) largely decentralized; department policies and practices were enacted autonomously with little oversight or intervention from the central administration. Indicative of this decentralized culture, was the policy that a negative vote of a faculty candidate at the department-level promotion and tenure committee meant that the candidate was denied tenure without ever going through further review either by the unit or university committees. The Provost changed this policy in 2009 as an effort to allow for greater coherence and more equitable review. This also helped to ensure that departmental decisions had to align with unit and university policies as well.

Leverage Points. Two important leverage points led to the development of intensive weeklong dialogues university-wide, and ultimately, the alignment of unit and department level policy to the university policy approved by faculty senate. One key leverage point was contained within the university's implementation report for section 4.3 (UNCG will promote an inclusive culture of engaged scholarship, civic responsibility, and community service (Engaged Scholarship)) of its 2009-2014 strategic plan. It was decided by strategic plan implementation committee members (including the lead author) that one piece of evidence for this goal would be the "\# (number) of departments that have revised P\&T guidelines to recognize and reward community-engaged scholars." This, among other measures, such as number and proportion of faculty, staff and students participating in community-engaged scholarship, supported with internal funds for community-engaged scholarship, and participating in professional development for community-engaged scholarship, would constitute a measure of support for community engaged scholarship.

The second leverage point was the legal necessity of aligning policies. Promotion and tenure policies are documents that might be, and have been, used by faculty members bringing lawsuits against the university to challenge decisions to deny their promotion and/or tenure. Discrepancies among policies at the various levels of faculty review could make the university vulnerable to future lawsuits of faculty who engage in nontraditional scholarly work and produce new forms of scholarship recognized in some policies but not in others. Relevant topics within the policy that required consistent alignment included not only community-engaged scholarship, but also contracted work, directed professional activities (faculty who take on significant administrative appointments), and nonacademic audiences and nontraditional mechanisms to produce and disseminate scholarly work.

Both of these leverage points were raised on a phone call that included Janke and Holland. At the conclusion of the call the Provost agreed to provide financial and political support for two events. First, a meeting with deans and executive leadership in Spring 2012, and second a week-long visit the following Fall (2013) to facilitate faculty dialogues. The Provost asked Janke and Holland to act as the planner, conveners, and facilitators of campus-wide dialogues. Inviting Holland as an external speaker to work alongside with Janke as an internal administrator was an important strategic decision. First, Holland brought with her significant national and international experience and perspective as a full professor and having served in executive administrative positions in similar institutions. Janke was able to interpret and translate UNCG's history and culture in such a way that the dialogues aligned with current conversations 
and contexts. Additionally, it was important that the dialogue continued through further documentation and dissemination, as well as through ongoing dialogues and consultation.

\section{Dialogue Design}

Three streams of related conversations were developed for the weeklong intensive dialogue process: (1) faculty dialogue on evaluating community engaged scholarly activities and products; (2) faculty dialogue on documenting community engaged scholarly activities and products; and (3) executive leadership and deans' council dialogue. We designed the dialogues to take place over the course of a week, creating an intensive time in which all participants (over 100 in total) received the same information at approximately the same time. This was intended to help create a sense of shared dialogue and to establish common views of the issues at hand, and possible strategies to address them effectively.

Inviting and Preparing Participants. The dialogue sessions, Cultivating and Rewarding the Mosaic of Faculty Scholarly Talents and Contributions, were designed to explore the specific issues across disciplinary areas of the various units and discuss potential ways forward. In his invitation letter to the September dialogues, which went out to all faculty, the Provost asked that all faculty who serve as department chairs or as reviewers of faculty candidates at the department- and unit-levels make room in their schedules to attend one of the sessions. The sessions were customized for particular disciplinary areas, though to accommodate busy faculty schedules, each was made available to any faculty member from any discipline. To ensure that the sessions addressed relevant and immediate questions and concerns of the department and units, several faculty members across the units were recruited to help inform the preparation of the relevant sessions.

In the sessions, Evaluating Community Engagement Scholarly Activities and Products in Promotion and Tenure, the participants were primarily individuals who served as reviewers who evaluate candidate dossiers, and department chairs who write letters contextualizing candidate's scope of work and responsibilities. Prior to and following all meetings, participants were asked to read three articles. We chose Scholarship Assessed: Evaluation of the professoriate, a special report published by the Carnegie Foundation for the Advancement of Teaching authored by Glassick, Huber and Maeroff (1997) to draw attention to existing standards of high quality scholarship, regardless of discipline, and including community-engaged scholarship. We chose the journal article Integration: Evaluating Faculty Work as a Whole by Colbeck (2002) to draw attention to the integration of faculty roles and the joint production of teaching, research, and service. Finally, Generation X Meets Theory X: What New Scholars Want authored by Trower (2006) raises awareness about generational differences among scholars with regards to expectations about faculty work and employment policy. Using the scholarly approach of identifying relevant literature from which to inform our collective dialogue served to model the process through which faculty members could build on existing knowledge to create new policies and norms.

Guiding the Dialogue Sessions. Each two-hour session began with brief introductions of names, departments, and titles. Then Holland engaged participants immediately in the questions: "When did you come to UNCG? How are things different now from that time?" These two questions were useful in revealing the broad generational differences between colleagues, and surfacing differences in experiences, perceptions, and perhaps, expectations about the identity of the university (formerly a much smaller teaching-focused Women's College, now a considerably larger high research activity university), as well as expectations for faculty work (e.g., changes in research-teaching-service balance; changes in committee work, reporting, or administrative obligations).

Next, Holland provided a brief discussion and presentation describing why community engagement is a strategy that matters for UNCG in a global and rapidly changing environment as a means to ask participants to think carefully about their P\&T environment and future success and reputation of UNCG 
(Holland, 2012). Participants explored evidence of community-engaged scholarship's relationship to quality teaching and student learning and satisfaction, as well as research activity. Holland reiterated the current generational shift, and the need to attract and retain faculty who fit the profile of this particular university. Lastly Holland emphasized that executive leadership needed to create a context for academic work, defining pathways of career progression, as UNCG is guiding (intentionally or not) the mosaic of talent of their faculty.

Much of the two-hour session focused on discussing of common and persistent issues related to community engagement, which also echo those in other innovative and high impact practices. Key points addressed were current developments in Academe regarding demographics, funding, accountability, public and political support, interdisciplinary and cross-sector collaboration, and nontraditional forms of scholarly activity and scholarship; changes in faculty view of academic employment policy; and standard definitions and indicators of high quality scholarship, and community-engaged scholarship in particular.

A key aspect of the session was to provide an applied experience wherein faculty participants were presented with a brief case study relevant to their field of a community-engaged scholars' dossier. These included brief descriptions of the fictional faculty member's research activities and products, curricular innovations, presentations on community engagement, local invited presentations, and community service. Activities and products listed were variously traditional, community-engaged, and serviceoriented in nature to reflect the diverse and complex scope of faculty work that is likely to include many forms of scholarship. The intention was to create a concrete and shared experience in which persistent issues related to the documentation and/or evaluation of faculty scholarship could be raised and discussed.

At the closing of each session, we discussed resources and next steps, and administered a brief survey to gain a better understanding of faculty perceptions about their ability to define, enact, and support community engagement across their academic roles. We shared the importance of coaching people who are enthusiastic about community engagement as a practice because it brings increased value to their work, but that they would need mentoring on being conscious about the importance of documenting this work throughout their academic careers. Many participants expressed a desire for input on suggestions for reporting community-engaged scholarship in the online format, as the system required faculty to make distinctions among the three traditional categories that may not be truly accurate in portraying the full scope and quality of faculty activity and productivity. We offered the continued opportunity for departments to work with ICEE on these topics and provided some additional facilitation (which a handful did request). We pointed all participants to the ICEE website, where we continued to curate extensive P\&T resources for faculty.

Linking Senior Administration to Faculty Dialogues. At the end of the week, Holland and Janke also met with executive leadership (chancellor, provost, vice chancellor for research and economic development) and members of the Dean's Council (convened by the provost) in two separate lunches. These lunches happened at the start and the end of the week, respectively, as a way to inform the delivery of the materials, as well as to provide some initial, high-level reflections about the faculty dialogues. The reflections were general and broad enough that they did not disclose the identities of the faculty members, departments, or units. Faculty members were made aware of the forthcoming luncheon with the deans, and the intention was to help inform them of key messages, as well as offer words of support and encouragement.

\section{Results of the Weeklong, Intensive Dialogue Sessions}

Participation in the eight faculty dialogues was broadly representative as it included individuals from 42 departments across seven academic units. Participants (reported across multiple roles) included 7 librarians/catalogers, 11 assistant professors, 22 associate professors, 30 professors, 7 directors, 5 
associate deans, and 3 deans. Of these, 21 faculty held department chair positions, and 26 served on a promotion and tenure committee at either the department, unit, or university-level.

Changes in Faculty Work. The opening conversation about the length of time faculty members had been employed at UNCG, and their perceptions of the relative changes over the years surfaced important differences that continue to affect the faculty rewards culture. Specifically, faculty described the increased workloads due to larger classes, an increasing number of students to advise and mentor, technological changes (e.g., personal computers, email, reporting systems), and increased requirements to collect and report student outcomes. Many also discussed the change in pedagogy and enrollment types from entirely residential to online courses, programs, and students. They described changes nationally and institutionally around research strategies and activities, naming changes in funding agencies and sources, increased emphasis on broader impacts of research, diversification of legitimate scholarly approaches and products, as well as venues for dissemination. They witnessed increased abilities (due to technological advances) and expectations to collaborate across departments, institutions, and sectors. Not least of all, the faculty named changes in student, faculty, and staff demographics, and their varied and changing expectations about the role and functions of higher education. Each of these beginning conversations throughout the week foreshadowed much of what Holland presented with regards to the changing nature of the university, and hence, provided a touchstone against which to personalize and make concrete the changes occurring at UNCG.

Evaluating New Forms of Faculty Work. As the conversation turned to the definition, role and value of community-engaged scholarship as one form of scholarship that is changing culture at UNCG, we found that, across all conversations with faculty in the various units, there appeared to be general acceptance of community-engaged scholarship as a legitimate strategy for teaching, research/creative activity, and service - as well as an understanding of the need to recognize, assess, and reward it. In this sense, faculty members stood behind the collective decision to write it into the university policy. Faculty also expressed a desire to better understand how to assess high quality scholarship of all types, including, but not limited to, community-engaged scholarship. The implications for how community-engaged scholarship were operationalized within the policy to become practice were not yet entirely clear to many participants.

While faculty across the dialogues generally supported the concept of community-engaged scholarship and viewed it as a legitimate form of faculty work, and 62 percent (48 total) of attendees reported having practiced a form of community engagement in the past two years, many faculty were still unsure about how to classify specific activities and artifacts related to community-engaged teaching, research/creative activities, and service. The question of "is it service, or is it community-engagement" was asked often, and was deeply explored in the dialogues in a way that has led to some new and shared understandings.

We perceived a general consensus across faculty that community engagement should lead to both traditional and non-traditional scholarly outputs. However, many faculty expressed concern that nontraditional publications and artifacts are less likely to be reviewed positively by department- and/or unitlevel peers. Several senior faculty members spoke about their hesitancy to advise and mentor junior colleagues to do this work while yet untenured. Even though the policy has changed, these faculty members felt that mindsets had not yet followed.

\section{Documenting and Sharing the Dialogue Themes}

Soon after the dialogues, the lead author wrote and distributed a follow up (Janke, 2012). The intention was to provide an overview of the dialogues while they were still "fresh." We also wanted to facilitate an ongoing dialogue about the perceived opportunities and lingering challenges related to operationalizing UNCG's collective commitment to recognize and reward community-engaged scholarship. The dialogues were also instructive for the Faculty Senate Scholarly Communications Committee - which was to host a 
forum on the related topics open-access publishing, technology transfer, and community engagement in promotion, tenure, and post-tenure review processes.

Subsequent to the letter, Janke, Medlin, and Holland authored and published the second volume of the Excellence in Community Engagement and Community-Engaged Scholarship titled, Honoring the Mosaic of Talents and Stewarding the Standards of High Quality Scholarship (2014). In it, we presented key ideas presented within Holland's weeklong visit, as well as suggestions for next steps. The Volume also included the voices of other national leaders in the field of community engagement who also visited UNCG during the 2012-2013 academic year as part of the Community Engagement Series. We asked them to share their thoughts on the changing landscape of higher education, and how and why this matters to UNCG as we position ourselves in an economic, political, and social climate that is radically different from previous eras. The following describes four "hotspots" included in the Volume as lessons learned by the UNCG dialogues, and which may inform future efforts at UNCG, and elsewhere, to support community-engaged scholarship.

\section{Dialogue Themes: Four "Hotspots".}

Following the meetings, the ICEE director and manager carefully reviewed extensive notes taken at each of the eight faculty dialogues to identify specific and key themes that seemingly functioned as barriers to the greater acceptance of diverse forms of scholarship, and to community-engaged scholarship in particular. Issues raised in at least four of the eight dialogues were labeled as "hotspots." We used the term "hotspots" drawing not on geology, but rather on hiking terminology, to describe those issues or questions that seem to "rub" up against one's values or beliefs in such a way that, if left untended to, can result in blistering disagreements and conflict. An experienced hiker learns to stop and address the irritation (hotspot), before a painful blister occurs.

Similarly, it is wise for faculty and administrators to identify and address directly the concerns, fears or anxieties that can arise from policies that challenge traditional notions by accepting increasingly diverse forms of scholarly approaches and artifacts. While derived from UNCG conversations, these hotspots are not unique to our faculty; they are echoed in national and international dialogues about communityengaged academic work as well. This is not only UNCG's journey, but a national and international one we share with others. These hotspots are important for informing future discussions, professional development, and strategic planning.

Hotspot \#1: how to define and value community engagement and outreach/public service. We found that faculty lack of consensus in how to define and value community engagement and outreach/public service in the face of needing to steward the rigor of scholarship and the review process. The question of "is it service or is it community engagement?" continues to persist among faculty according to the dialogues. Therefore, while community-engaged scholarship is codified in policy and many colleagues identify as community-engaged scholars, a common understanding of what it is and why it matters is not universal across faculty.

Community engagement and public service are definitionally distinct from one another, as defined by UNCG and national standards, such as the Carnegie Foundation. Although ICEE had developed, published, and presented the definitions at faculty senate and shared it widely in meetings and online, there was continued need to raise awareness about national conversations and concepts. We used the Carnegie Foundation's (n.d.) definitions: Community engagement describes collaboration between institutions of higher education and their larger communities (local, regional/state, national, global) for the mutually beneficial exchange of knowledge and resources in a context of partnership and reciprocity. Public service/outreach describes activities and services planned and offered by the institution or its staff 
to the community for public consumption (one-way activity) (Kellogg Commission, 2001). In all written and spoken statements, ICEE staff have emphasized that both community engagement and public service are essential to the university mission.

Hotspot \#2. Honoring the spectrum of scholarship. General consensus existed across faculty members attending the dialogues that community engagement should lead to both traditional and non-traditional scholarly outputs. Despite this commonly held agreement, several faculty members attending the dialogues expressed concern that non-traditional publications and artifacts are less likely to be reviewed positively by department- and/or unit-level peers. For example, how does one assess the "impact" of 5,000 "hits" on a website, a white paper that influenced a state policy or law, or a curriculum or business plan? How do these "count" relative to an academic, peer-reviewed manuscript or book chapter?

Across dialogues, faculty tended to express individual support, but that when making a collective decision, the support might be overshadowed and overcome by the lack of support from colleagues. Further, faculty worried that agreements made at the time of hire or early on in one's career about a nontraditional or community-engaged agenda might not be honored later on due to changes in personnel, particularly in department chairs and deans, but also faculty peers. One department chair shared, "The scariest thing I've ever done was try to mentor a new faculty member in which we talk this talk (supporting community-engaged scholarship), and the question of 'when I go up for tenure will they walk the walk' - you're dealing with career decisions of someone young and junior."

Part of the challenge expressed above is that some faculty reviewers do not feel fully prepared and skilled to fairly and accurately assess community-engaged scholarship. A series of challenging and persistent issues make it difficult to evaluate the quality, impact, and eminence of nontraditional forms of scholarship and reveal a need for further faculty development. Faculty reiterated the problematic issues raised by Drs. Holland and Janke in their presentation, including: nontraditional dissemination venues (e.g., online journals, blogs); attribution in truly collaborative and/or interdisciplinary work; identifying appropriate and qualified peers to evaluate scholarship; how to define what impact means and to what communities (internal disciplinary community/academic, as well as external community/public); and, how to appropriately include and evaluate contracts and consultations.

These challenges were represented in comments such as these: "Our biggest challenge to awarding and assessing community-engaged scholarship is ... how we discern attribution, roles, and reaction of community when we're not used to having non-academic voices giving us feedback on academic activity." Another faculty member said, "What's difficult for me is, which is more important? What the (community) receivers report as impact versus (what) peer (academic) reviewers ... say is impact. What is more important in community-based stuff? What are the respective weights?" The dialogues offered opportunities for participants to explore some of these issues, resulting in participants suggesting the need for further opportunities to learn more about how to evaluate the quality, impact, and eminence of nontraditional forms of scholarship.

Paper surveys distributed to faculty members participating in the dialogues supported this finding: approximately 75 percent of all respondents $(\mathrm{N}=84)$ felt "not able/prepared" or only "somewhat able/prepared" to assist or mentor a colleague to develop (70\%) or document (77\%) community-engaged scholarship, or to evaluate and assess the quality of community-engaged scholarship (teaching $=75 \%$; research/creative activity $=68 \%$; service $=75 \%$ ). Additional survey findings can be found at the end of this document.

Because there are two communities towards which the engaged scholar is expected contribute, the challenge of traditional ways of "counting" or giving preference to traditional modes and products over nontraditional modes and products is that it requires community-engaged scholars to do more work than 
the "traditional" scholar. That is, s/he has to produce the same number of traditional articles, books, book chapters, and disciplinary contributions as her or his "traditional" colleague in addition to the nontraditional products/artifacts (white papers, program evaluations, videos, websites, etc.), expected to fulfill obligations to non-academic community partners. Furco's (2013) diagram on the measuring the impact of engaged scholarship shows that community-engaged scholars ultimately have two trajectories of impact: academic and community audiences.

Hotspot \#3: stewarding the rigor of scholarship. Faculty shared their desire to support engaged scholars through clear and equitable evaluation processes. However, many department chairs and mentors shared their concerns about how to advise on the documentation and evaluation of the quality, impact, and eminence of nontraditional forms of scholarship.

The standards for high quality scholarship (see page 7) also apply to community-engaged scholarship. Numerous scholars drew from the criteria presented in "Scholarship Assessed: A Special Report on Faculty Evaluation,"18 which have been adapted by respected networks and associations, such as the National Review Board for the Scholarship of Engagement and Community-Campus Partnerships for Health (CCPH). These groups have established consensus on the common standards as applied to community-engaged scholarship, and provide concrete review criteria that can be used to clearly evaluate collaborative processes and nontraditional products.

Community-Campus Partnerships for Health provides an especially helpful tool to help scholars evaluate both the process and product of community-engaged scholarship. CCPH created CES4Health.Info, a free online mechanism for peer reviewing, publishing, and disseminating products of health-related community-engaged scholarship that are in forms other than journal articles and that address both process and product. Specifically, to assess the quality of community-engaged scholarship, one must evaluate both the project process through which the product was developed and the product itself to determine whether it is of high quality. Therefore, faculty candidates should present (and evaluators must review, in addition to the product or artifact) a reflective critique of the community-engaged processes that led to the development of the products listed/presented in the dossier to fully assess the quality of communityengaged scholarship. Additionally, peer review should be assigned to community and academic reviewers who have relevant areas of expertise associated with the activity and its outputs. Reviewers assess both submitted products and an accompanying application. By providing information in the application about the work or project that led to the development of the submitted product, as well as about the product itself, reviewers receive additional information on which to base decisions:

Project Process Evaluation: To evaluate the project process as to whether it meets the standard criteria for high quality, community-engaged scholarship requires the faculty member whose work/dossier is under review to provide a thick description of the goals, preparation, and methodological rigor, as well as the significance and presentation/dissemination of their engaged scholarship.

Project Product Evaluation: To evaluate products as to whether they meet standard criteria for high quality, community-engaged scholarship, a reviewer may examine the product as well as review the candidate's narrative. In some cases, evidence of the methodological rigor of the product will be embedded within a faculty member's narrative. For example, in the case of videos, curricula, or policy briefs, choices about the aims, design, approaches used are not likely to be described within the product itself, and therefore, evidence of rigor must be explained/provided in the faculty members' narrative that describes this work. 
Hotspot \#4: The three bucket problem. The "three bucket problem," or how to disaggregate academic work roles that are increasingly experienced by faculty as integrated activities - was expressed by some faculty as a frustration and a barrier to the accurate representation of faculty productivity, regardless of whether the work was community-engaged; others felt that the traditional divisions should be maintained. While faculty appeared to reach agreement that faculty roles are often and positively integrated, the format for submitting one's dossier for review requires that faculty candidates make distinctions among the three traditional categories that may not be truly accurate in portraying the full scope and quality of faculty activity and productivity. Community-engaged scholars, among others, may be disadvantaged in reporting and uploading documents into the online documentation system as it appears to force them to disentangle and differentiate integrative academic work which may be intentionally and/or necessarily integrated.

Questions about the relative importance ("weight") of teaching, research/creative activity, and service as indicated by hiring, promotion, and tenure decisions were also raised in four of the seven dialogues. Faculty discussed the changing identity of UNCG and efforts to increase the amount of research, and particularly external funding. According to faculty, successful candidates for hire to a tenure track position, as well as promotion and/or tenure, must have not only an active and successful record of research/creative activity, but also of external funding. The importance of being an active and successful researcher and grant writer appeared to overshadow faculty members' perceived ability to hire or reward faculty members whose scholarly portfolios do not meet that particular standard. A faculty member shared with his/her colleagues: "We're a teaching university with a research identity and Ph.D. programs throughout that give us labels of a Ph.D. institution. It's challenging. Have to be both identities at 100 percent. There's no way to do either teaching OR research half way. Research is important because of pubs, but the teaching is the work that is required." Another faculty member shared, "Now in my department we make it explicit in hiring new faculty that we expect them to be an active seeker/attainer of external funds." Across the participants, there are differing views on the relative importance of attention to research/creative activity and teaching quality, in particular. At the same time, each dialogue ended with the majority of participants indicating a greater understanding of community-engaged scholarship as an integrative form of both teaching and research/creative activity.

Faculty Self-Perceptions about Abilities and Preparation. Overall, our discussions aligned with a faculty survey about community engagement that was administered at each of the sessions. The survey was intended to provide a quick "temperature check" to identify general perceptions about communityengaged scholarship. Our findings based on a 76 percent response rate showed that those who attended ICEE-sponsored events in 2012-13 felt most able/prepared to define service-learning and communityengaged scholarship, but felt relatively less able/prepared to design, document, evaluate, or mentor various aspects of community-engaged scholarship. The dialogues were instrumental to our ability to interpret these findings, and to establish some pathways for increasing faculty members' capacity to do, support, and evaluate community-engaged scholarship.

\section{Conclusion}

This article provides a richly descriptive narrative of one metropolitan university's efforts to create deep and sustained cultural change that is embedded and codified in promotion and tenure policies. This is a journey that is increasingly shared with other institutions as they prepare for a future that is very different from the past, in many critically important ways. In the face of decreased public and financial support for public higher education, increased accountability requirements for performance outcomes, fewer student enrollments, and rapid turnover of faculty and staff, how does an institution make itself distinctive so that it becomes the first choice of the students, faculty, and staff that it wants to attract? How do we intentionally prepare for the culture shift that will emerge as the baby boomer "bubble" moves through 
the academy and is replaced new generations of faculty? These individuals hold very different ideas of what scholarship is, what it means, how it is expressed, and how it should be evaluated. Situated within the realities of these changing academic demographics, characteristics, and norms, prioritizing the alignment of promotion and tenure policies and practices in ways that support new and emerging forms of high quality scholarship is especially critical. Change is coming, how are our policies and practices prepared to leverage this opportunity in strategically advantageous ways?

As UNCG faculty and staff began writing its recertification application in Fall 2014, two years after the dialogues, UNCG celebrated the alignment of all 54 departments, and all unit guidelines to the universitywide documents. Several faculty members have continued to be tenured and promoted each year who practice community-engaged scholarship. And, formal conversations have led to the implementation of new language in some departments' non-tenure track faculty performance expectations and reviews. UNCG also has its own stories of faculty who were attracted to UNCG because of the university's explicit support for community engagement in promotion tenure policies, as well as within the departments', units', and institution's culture and practices more broadly.

Other examples tell stories of faculty support, and indeed, encouragement for community-engaged scholarship continue as part of the UNCG narrative and its institutional identity. For example, faculty who reviewed internal grants for faculty scholarship, on their own volition, have begun to "give more weight" for those who engage students and community partners in their scholarship. The practice and value of community engagement at UNCG was expressed throughout the more than 40 listening sessions held by the university's new provost in 2014 (UNCG Tomorrow, 2014). Finally, results from the spring 2015 COACHE (The Collaborative on Academic Careers in Higher Education) survey showed that UNCG faculty rated satisfaction with its tenure policies and tenure clarity higher than faculty at selected peer institutions and at most similar sized institutions. These were listed as the institutions highest rated strengths, along with divisional leadership and departmental quality. Although one cannot say that these processes and dialogues are the direct cause for the increased support of community-engaged scholarship and satisfaction with promotion and tenure guidelines and clarity, it is plausible to suggest that the years of informed and facilitated dialogue, documentation, and practice have contributed to the positive and supportive outcomes.

The experience of UNCG's path towards greater institutional and cultural support for community engagement may be instructive to others that are already on a shared journey, as well as those who are yet to embark upon their own. Here we share some suggestions gained through our own lessons learned.

Faculty and administrative leaders are encouraged to celebrate, as well as reinforce, the steps already taken to operationalize commitment to community-engaged scholarship in promotion and tenure policies and practices. Operationalizing community-engagement has an unavoidable learning curve because nontraditional activities and artifacts challenge more familiar ways of documenting and evaluating scholarship. While one's campus may have further to go on its journey to understand and operationalize community engagement as a scholarly method, progress is to be applauded as a way of creating positive forward momentum.

Campuses are encouraged to create open space for informed conversations across faculty ranks, departments, and administrative levels to foster shared understanding about the types of scholarly activities and contributions that are valued, encouraged, and rewarded, as well as the best practices for documenting and evaluating the quality, impact, and eminence of community-engaged and other forms of emerging and nontraditional scholarship of all types. Dialogues are essential to surface latent questions, concerns, and even fears. Without a common and shared understanding among faculty across all ranks and units, faculty tend to act conservatively choosing not to recognize newer forms of scholarship. Questions about differentiated workloads and whether other senior colleagues value the communityengaged scholarship of junior faculty members remain hidden, and lead faculty to provide conservative 
advice to candidates, and to be conservative in their own decisions. Left unaddressed, faculty may unconsciously and unwittingly reinforce ideas and decisions that they do not actually hold themselves because of their perceptions of others' views. Additional and sustained rounds of informed dialogues can build further institutional consensus and clarity regarding a way forward.

Related to the second recommendation, it is important to provide informed opportunities to practice addressing known common and persistent issues prior to evaluating candidate's applications. As was apparent in the dialogues, the "devil is in the details." Faculty, particularly those serving on promotion and tenure review committees, are encouraged to collect examples of nontraditional faculty work activities and artifacts -- both community-engaged and other forms -- and to use them for practice and discussion prior to reviewing the actual work of candidates. Advances and evolutions in technology, as well as epistemologies and pedagogies, have greatly affected the ways in which scholarship is generated and expressed, as well as the nature and scope of its dissemination and impact. Just as qualitative researchers take measures to maximize inter-rater reliability to ensure shared interpretations of data, committee members are encouraged to take measures that ensure fairness and equity when evaluating candidates' dossiers.

At a very practical and technical level, campuses are encouraged to evaluate the effectiveness of the online system for submitting candidates' materials for promotion and tenure in light of faculty dialogues about the "three bucket problem." Across the dialogues, faculty discussed the challenge of separating teaching, research/creative activities, and service into separate areas, per the instruction of the guidelines and the structure of the online system. Separation, it was argued, does not allow for an accurate portrayal of faculty work and, in some cases, prevents department chairs from presenting and faculty from documenting the full scope of their work productivity. The growing body of research on effective documentation of faculty work and the challenges of separating this work into different categories should be fully explored.

Finally, as preparations are being made for institutions' desired futures, it is essential to capitalize on all existing assets. This includes the strengths and assets of senior faculty who will continue to hold significant leadership positions amongst the faculty and administration for the next decade. In the midst of the cultural shift, how do we support the engagement of senior faculty? What support might they need if they are to support a future that (like others of any generation) they cannot envision with certainty and which they certainly will not be a part of. Inclusion, support, and development among all faculty is important to avoid cultural clashes that can lead to workplace incivility, resulting in wasted resources, not the least of which is time.

Ultimately, more attention must be paid to the professional development of senior faculty in the art and science of coaching. Higher education models of mentoring, wherein senior faculty provide advice to junior faculty on how to "make it," particularly through the process of reappointment, promotion and tenure, may be outdated and outmoded. New models of academic leadership would benefit from examining more facilitative, asset-based coaching approaches in which senior faculty are not leaders, but guides who practice appreciative inquiry and reflective listening, and who share thoughtful questions in an effort to help more junior faculty to build strategies and confidence to develop their own vision, planning, and prioritization for the future. Asset-based dialogue and coaching approaches are skills that can be developed, and should be developed and practiced by all faculty as a way to facilitate difficult conversations in ways that promote positive interpersonal communication (Stone, Patton \& Heen, 2000; Wilmot \& Hocker, 2001; Reimer et al., 2015). These are democratic skills to be developed and practiced within the university, and which are core skills for community-university partnerships. 


\section{References}

Battistoni, R. M., Gelmon, S. B., Saltmarsh, J. A., Wergin, J. F., \& Zlotkowski, Edward. (2003). The engaged department toolkit. Providence, RI: Campus Compact.

Boyer, E. L. (1990). Scholarship reconsidered: Priorities of the professoriate. Princeton, N.J.: Carnegie Foundation for the Advancement of Teaching.

Carnegie Foundation for the Advancement of Teaching. (2015 January 11). All community engagement classified institutions: 2010 and 2015. Retrieved from

http://nerche.org/index.php?option=com_content\&view=article\&id=341\&Itemid=92.

Colbeck, C. L. (2002). Integration: Evaluating faculty work as a whole. New Directions for Institutional Research 2002 (114), 43-52. doi: http://dx.doi.org/10.1002/ir.45

Furco, A., \& Holland, B. A. (2004). Institutionalizing service-learning in higher education. In M. Langseth \& W. M. Plater (Eds.), Public Work and the academy: An academic administrator's guide to civic engagement and service-learning (pp. 23-39). Bolton, MA: Anker Publishing Company.

Glassick, C. E., Huber, M. T., \& Maeroff, G. I. (1997). Scholarship assessed: evaluation of the professoriate. San Francisco: Jossey-Bass.

Holland, B. A. (1997 Fall). Analyzing institutional commitment to service: A model of key organizational factors. Michigan Journal of Community Service-learning 4 (1), 30-41.

Holland, B. A. (2012). Cultivating and rewarding the mosaic of faculty scholarly talents and contributions [PowerPoint Slides]. Greensboro, NC, September 17, 2012.

Janke, E.M., \& Clayton, P.H. (2011). Terms and definitions for community engagement in UNCG promotion and tenure guidelines. Retrieved from http://communityengagement.uncg.edu/wpcontent/uploads/2014/07/Terms-and-Definitions-for-Community-Engagement-in-UNCG-Promotion-andTenure-Guidelines.pdf.

Janke, E. M., \& Clayton, P. H. (2012). Excellence in Community Engagement and Community-Engaged Scholarship: Advancing the Discourse at UNCG (Vol. 1). Greensboro, NC: University of North Carolina at Greensboro.

Janke, E. M. (2012). Report: Documenting and evaluating the mosaic of faculty scholarly talents and contributions. Retrieved from http://communityengagement.uncg.edu/wpcontent/uploads/2014/07/Documenting-and-Evaluating-the-Mosaic-of-Faculty-Scholarly-Talents-andContributions.pdf.

Janke, E. M., Medlin, K. D, \& Holland, B. A. (2014). Honoring the Mosaic of Talents and Stewarding the Standards of High Quality Community-Engaged Scholarship. Excellence in Community Engagement \& Community-Engaged Scholarship. Vol. 2. University of North Carolina at Greensboro: Institute for Community and Economic Engagement. 
Janke, E., \& Hayes S. (2010). My department calls me Mr. Community: Exploring the experiences and scholarly products of community-engaged faculty. Paper presented at the Lilly Conference on College and University Teaching. Greensboro, NC.

Kecskes, K., Gelmon, S.B., \& Spring, A. (2006). Creating engaged departments: a program for organizational and faculty development. To Improve the Academy 24, 147-165.

Kecskes, K., Ed. (2006). Engaging departments: Moving faculty culture from private to public, individual to collective focus for the common good. Boston, MA: Anker Publishers.

Kellogg Commission. (2001). Returning to our roots: Executive summaries of the reports of the Kellogg Commission on the future of state and land grant universities. Washington DC: National Association of State Universities and Land-Grant Colleges.

Lederach, J. P. (2003). The little book of conflict transformation. Intercourse, PA: Good Books.

O’Meara, K. (2002). Motivation for faculty community engagement: Learning from exemplars. Journal of Higher Education Outreach and Engagement 12 (1), 7-29.

O’Meara, K., Sandmann, L., Saltmarsh, J., \& Giles, Jr., D. (2011). Studying the professional lives and work of faculty involved in community engagement. Innovative Higher Education 36 (2), 83-96. doi: http://dx.doi.org/10.1007/s10755-010-9159-3

Reimer, L., Schmitz, C., Janke, E., Askerov, A., \& Matyók, T. (2015). Transformative change. Lanham, MA: Lexington Books.

Stone, Douglas, Bruce Patton, \& Sheila Heen. (2000). Difficult Conversations: How to Discuss What Matters Most. New York: Penguin.

Sugar, J., Pruitt, K., Anstee, J., \& Harris, S. (2005). Academic administrators and faculty retirement in a new era. Educational Gerontology, 31, 405-418. doi: http://dx.doi.org/10.1080/03601270590921672

Trower, C. (2006). Gen X meets theory X: What new scholars want. Journal of Collective Bargaining in the Academy 0 (1), 11. Retrieved from http://thekeep.eiu.edu/jcba/vol0/iss1/11.

Vogelgesang, L. J., Denson, N., \& Jayakumar, U. M. (2010). What determines faculty-engaged scholarship? The Review of Higher Education, 33 (4), 437-472. doi:

http://dx.doi.org/10.1353/rhe.0.0175

UNCG Tomorrow: UNC Tomorrow Response Phase I. (2008). Retrieved from https://old.northcarolina.edu/nctomorrow/UNCG.pdf.

UNCG Tomorrow: Emergent Themes from Stakeholder Vision Forums. (2014). Retrieved from http://uncgtomorrow.uncg.edu/AdditionalPlanningDocuments/Emergent-Themes/themes.php

Wilmot, W., and Hocker, J. (2001). Interpersonal Conflict (Sixth Ed.) New York: McGraw Hill. 


\section{Author Information}

Emily M. Janke, Ph.D. is the founding director of the Institute for Community and Economic Engagement at the University of North Carolina at Greensboro, and an associate professor in the Peace and Conflict Studies Department. Her teaching, scholarship, and administrative roles explore and build upon multiple aspects of community and economic engagement, including community-university relationships and partnerships, institutional culture and change strategies, and the role of reciprocity, communication, and tension in collaborative relationships for public good.

Emily M Janke, Ph.D.

3710 Moore Humanities and Research Administration

PO Box 26170

Greensboro, NC 27402-6170

Phone: 336-256-2578

Email: emjanke@uncg.edu

Barbara A. Holland, Ph.D. is a researcher and consultant focusing on organizational change in higher education with a particular interest in the influence of community engaged scholarship on academic culture and institutional success. She is a Distinguished Professor of Community Engagement at University of Nebraska Omaha, Senior Scholar at Indiana University-Purdue University Indianapolis, and Adjunct Professor at Portland State University.

She resides in Portland, Oregon

Barbara A. Holland

Phone: 503-638-9424

Email: holland.barbaraa@gmail.com

Kristin D. Medlin, MPA served as a graduate assistant and then as the founding manager for partnerships and communications in the Institute for Community Engagement at the University of North Carolina at Greensboro from 2011-2015. During this time, she helped to establish the protocols, practices, and platforms for collecting comprehensive, university-wide information about community engagement and public service. She is now the assistant director for postsecondary initiatives at TreeTop Commons, and is pursuing a graduate degree in Educational Research Methodology at the University of North Carolina at Greensboro.

Kristin D. Medlin, MPA

TreeTop Commons, LLC 3001 Charolais Drive Greensboro, North Carolina

Telephone: 336.907.6921

Email: kdmedlin@uncg.edu 